\title{
Drug Obsolescence
}

\section{Marcelo S Ramos*}

Cancer Center A.C. Camargo and Hospital University, University of São Paulo, São Paulo, Brazil

*Corresponding author: Ramos MS, Cancer Center A.C. Camargo and Hospital , University of São Paulo, São Paulo, Brazil, Tel: +5511981422810; Fax: +5511981422810; E-mail: Fred.Chow@anu.edu.au

Rec date: June 14, 2016, Acc date: June 22, 2016, Pub date: June 24, 2016

Copyright: @ 2016 Ramos MS. This is an open-access article distributed under the terms of the Creative Commons Attribution License, which permits unrestricted use, distribution, and reproduction in any medium, provided the original author and source are credited.

Keywords Drug obsolescence; Rocuronium; Succinylcholine

\section{Introduction}

What makes a drug obsolete? The obvious answer is the appearance of a new drug, but this new drug must beat the old one in one (or preferably in all) of the three features: pharmacodynamics, pharmacokinetics and side effects. As a general rule the newer drug is always much more expansive than the older, and as we evolve to a more exigent society it will cost more and more since more trials and test are requested for any new drug.

Concerning airway management there is an important question is: Is succinylcholine obsolete?

In order to be deemed obsolete the new drug must address the three features: regarding pharmacodynamics we cannot state that rocuronium beats succinylcholine. The short latency of succinylcholine cannot be beaten even with great overdoses of rocuronium; but it is a close race. Regarding pharmacokinetics it is not even close, but there is the combination of rocuronium with sugammadex can be taken as an alternative for succinylcholine as it provides immediate reversible neuromuscular blockade. Regarding side effects there is a clear advantage for the new drug (I am considering as the "new" drug the pair rocuronium /sugammadex, not the rocuronium only). No one has to consider increases either in intraocular pressure or potassium levels when using the "new" drug.

But, and there is always a "BUT", I consider that what is really obsolete is not succinylcholine, but the old fashioned dose $(1 \mathrm{mg} / \mathrm{kg})$ used most often. Every lecture I present, I show the very well-known graphic that depicts the time line of Oxygen saturation fall as the minutes passes for several kinds of patients, and the lower box at 7 to 10 minutes that depicts termination of effect of succinylcholine. If we use a smarter dose of succinylcholine we can bring this "lower right box" to a much "more safe left", making even sicker patients able to resume ventilation before saturation goes really south (Figure 1). Literature cites $0.6 \mathrm{mg} / \mathrm{kg}$ [1-3], but in my experience I use smaller doses $(0.25$ to $0.4 \mathrm{mg} / \mathrm{kg})$.There is a "built-in" safety mechanism in succinylcholine, its fast action due to metabolism (let's not consider the very rare atypical cholinesterase patients). In order to the pair rocuronium /sugammadex to have short action, there is the need of an active decision making by the anesthesiologist, who are to declare his inability to intubate and the decision to wake up the patient. This decision may be seen as a declaration of incompetence (actually this is the wisest decision).

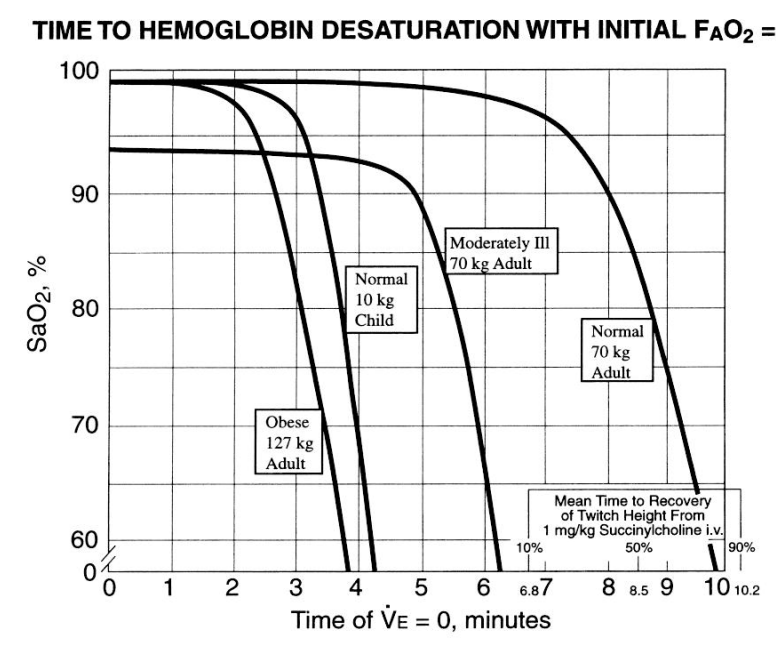

Figure 1: Mechanism of action succinylcholine.

Without very serious commitment with the safety of the patient, a less reassured anesthesiologist is prone to be fixated on the mistake of trying to intubate until he succeed or the patient dye, no matter what occurs first. The intubation becomes not an act to help the patient anymore, but a matter of honor to the (poorly educated) anesthesiologist. If the neuromuscular block disappear spontaneously, (succinylcholine) the anesthesiologist is compelled to assume that the "intubation game is over", and it is time to try an awake intubation. To persist in the error and administer a second succinylcholine dose is possible only after passing through the barrier of another active decision that disregards many instructions and guidelines, and so, this second dose may be hindered by a glimpse of common sense.

\section{Conclusion}

My conclusion is that succinylcholine is not obsolete! What is obsolete is the (not so wise) use of the common large (and unnecessary) dose of $1 \mathrm{mg} / \mathrm{kg}$, which yields no more relaxation (in practical terms) than a smaller dose. The inclusion of the pair rocuronium/sugammadex is a very welcome acquisition to our arsenal, but it is not enough to make succinylcholine obsolete. And I am not even considering costs in this analysis.

\section{References}

1. Kopman AF, Zhaku B, Lai KS (2003) The "Intubating Dose" of succinylcholine: the effect of decreasing doses on recovery time. Anesthesiology 99: 1050-1054. 
Citation: Marcelo S Ramos (2016) Drug Obsolescence. Gen Med (Los Angeles) 4: 260. doi:10.4172/2327-5146.1000260

Page 2 of 2

2. El-Orbany MI, Joseph NJ, Salem MR, Klowden AJ (2004) The neuromuscular effects and tracheal intubation conditions after small doses of succinylcholine. Anesth Analg 98: 1680-1685.
3. Naguib M, Samarkandi A, Riad W, Alharby SW (2003) Optimal dose of succinylcholine revisited. Anesthesiology 99: 1045-1049. 